\title{
Severe haemolysis associated with hepatitis A and normal glucose-6-phosphate dehydrogenase status
}

\author{
D J Lyons, J M Gilvarry, J F Fielding
}

\begin{abstract}
We report massive acute haemolysis associated with hepatitis A in a 36 year old Irish woman. Although mild anaemia is not uncommon during viral hepatitis, haemolysis of the severity observed in this patient has previously been reported only in patients with glucose-6phosphate dehydrogenase deficiency.
\end{abstract}

\section{Case report}

A 36 year old woman presented in December 1987. She had been unwell for four weeks, initially with fatigue and anorexia, followed two weeks later by episodes of shivering and fever. Five days before presentation she had noticed pruritus, jaundice, pale stools, and dark urine. Regular medications included the contraceptive pill and a compound preparation containing ephedrine, phenobarbitone, and theophylline which she took for asthma. In addition she had occasionally taken mefenamic acid and paracetamol for headaches.

On admission to hospital she had lemon yellow icterus. No signs of chronic liver disease were detected and the physical examination was otherwise unremarkable. Initial investigations showed a haemoglobin concentration of $14.6 \mathrm{~g} / \mathrm{dl}$, a white cell count of $10 \cdot 2 \times 10^{9} / 1$ with a normal differential, and platelets $252 \times 10^{\circ} / 1$. Clinical chemistry indicated a mixed cholestatic/ hepatocellular disorder. Her total bilirubin concentration was $296 \mu \mathrm{mol} / \mathrm{l}$ (Figure), aspartate transaminase was 197 , alanine aminotransferase was 484 , alkaline phosphatase was $2054 \mathrm{IU} / \mathrm{l}$, and gammaglutamyl transferase was 728 IU/1. Ultrasound examination of the liver showed a normal biliary tree with no evidence of calculi in the gall bladder. A liver biopsy specimen showed intra-

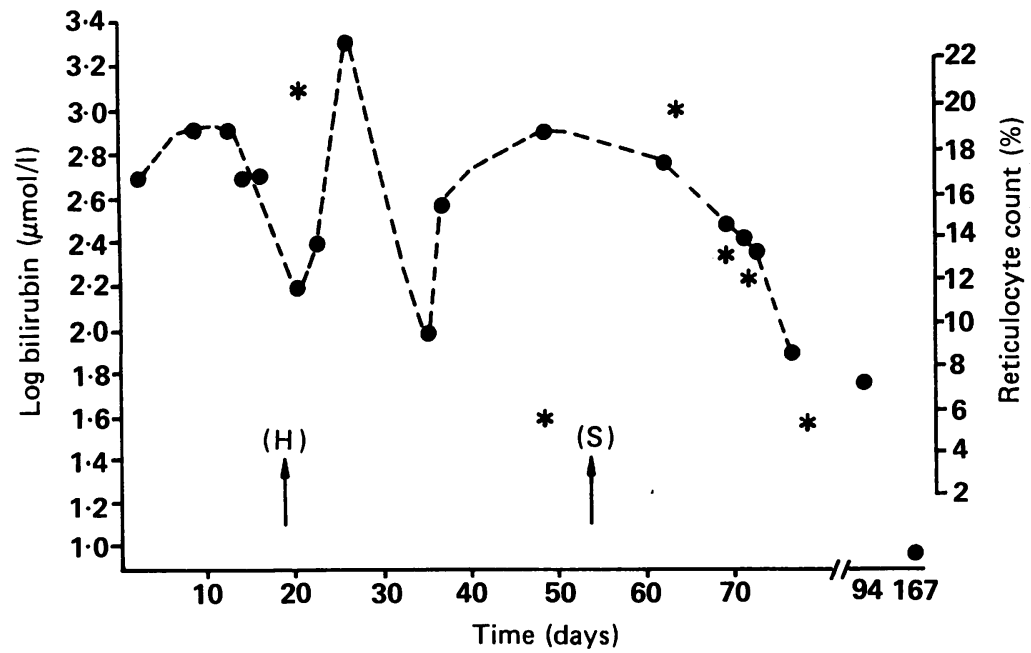

Changes in the patient's bilirubin concentration (O) and reticulocyte count (*). The onset of haemolysis is indicated by $(H)$ and the start of steroid treatment by $(S)$. hepatic cholestasis and a cellular infiltrate comprised of lymphocytes, plasma cells, and eosinophils. Immunoglobulin antibodies to hepatitis A virus were detected.

Because of persistent and deepening jaundice she remained in hospital. On the 18th day she complained of breathlessness and feeling faint. Her haemoglobin concentration had fallen to $4.4 \mathrm{~g} / \mathrm{dl}$, there was a reticulocytosis of $21 \%$. a direct antiglobulin test was positive showing IgG antibodies, and serum haptoglobins were reduced at $0.38 \mathrm{~g} / 1$ (normal range $0.7-3.8 \mathrm{~g} / \mathrm{l}$ ). A diagnosis of acute autoimmune haemolytic anaemia was made. The patient was given a transfusion and her general condition stabilised. Over the next five weeks a low grade haemolysis persisted, the haemoglobin fell by $4 \mathrm{~g} / \mathrm{dl}$, and the reticulocyte count remained above $6 \%$. She was readmitted to hospital and treated with high dose oral prednisolone. The Figure shows the relation between her bilirubin concentrations and reticulocyte count and the onset of haemolysis and treatment with prednisolone. Her general well-being improved and there was a gradual rise in her haemoglobin value. She made an uneventful recovery and nine months after discharge remains well and off steroids. Glucose-6phosphate dehydrogenase activities measured six months after transfusion were within normal limits.

\section{Discussion}

We report a patient with hepatitis $A$ associated with cholestasis and with massive acute haemolysis. Cholestasis is a well recognised event in hepatitis $A$, though its frequency is poorly documented. ${ }^{\prime}$ Three possible mechanisms may explain the haemolysis observed in our patient. Firstly, it may have been drug induced. We believe that this is unlikely as we have not been able to find a report of any of the medications taken by this patient being causally linked with haemolysis. Secondly, the two conditions may have occurred simultaneously, through chance alone. Fifty six per cent of Irish blood donors have antibodies to hepatitis $\mathrm{A}$ virus (personal communication). Assuming that the incidence of hepatitis $A$ is between one and two per cent and that of autoimmune haemolytic anaemia is in the region of $1: 80000^{2}$ the two diseases might occur by chance in the Republic of Ireland (population 3.5 million) once in two to four years.

We believe that a more probable explanation is that the haemolysis occurred as a complication of hepatitis A. Mild anaemia occurring during the course of viral hepatitis is common and is likely to be caused, in part at least, by shortened red cell half life. ${ }^{3}$ The reduction of red cell half life is 
incompletely understood but has been attributed to abnormal glutathione metabolism. ${ }^{+}$This may explain the increased frequency and severity of haemolysis in patients with glucose-6-phosphate dehydrogenase deficiency.

It is difficult to assess the frequency with which severe haemolysis occurs in hepatitis A. Many reports antedate the serological tests which distinguish between hepatitis $A$ and hepatitis B..$^{6-8}$ Conrad and Schwartz found shortened red cell survival in five of 25 adult patients with viral hepatitis. ${ }^{3}$ Kattamis and Tjortjatou found evidence of mild haemolysis during viral hepatitis in 24 of 104 children with normal glucose-6-phosphate dehydrogenase activities. ${ }^{9}$ Upadhyaya et al found mild haemolysis in 28 of 86 patients with acute viral hepatitis and normal glucose-6-phosphate dehydrogenase activities, though serological tests for hepatitis B and hepatitis A do not seem to have been carried out. ${ }^{10}$ In contrast, Eliakim et al ${ }^{11}$ studied age and sex matched patients serologically negative for hepatitis $B$. The patients were divided into two groups - those with glucose-6phosphate dehydrogenase deficiency and those normal values. No patient of the 26 with normal values had haemolysis, whereas 12 of the 17 with deficiency had haemolysis. Massive haemolysis, such as occurred in our patient, has previously been recorded only in glucose-6phosphate dehydrogenase deficient patients. ${ }^{23}$ We have found one report ${ }^{12}$ of haemolysis complicating hepatitis $\mathrm{A}$ in the presence of normal glucose-6-phosphate dehydrogenase values. This patient was a 62 year old Japanese woman with mild haemolysis (haemoglobin $10.4 \mathrm{~g} / \mathrm{dl}$, reticulocyte count $2 \%$ ) comparable to that found in some of the children with normal glucose-6phosphate dehydrogenase values studied by Kattamis and Tjortjatou. ${ }^{9}$
We believe that the patient described here represents a very unusual occurrence: massive haemolysis in the presence of hepatitis A. While she improved dramatically on oral prednisolone it is not possible to deduce the role of this treatment in the subsequent return of her bilirubin concentration to normal. Deepening jaundice in acute viral hepatitis without deterioration in clinical or biochemical parameters of liver function should arouse suspicion of this complication.

1 Gordon S, Reddy R, Schiff L. Prolonged intrahepatic cholestasis secondary to hepatitis A. Ann Intern Med 1984 101: 635-7.

2 Worlledge $S$. The autoimmune haemolytic anaemias: In: Hardisty $\mathrm{R}$, Weatherall $\mathrm{D}$, eds. Blood and its disorders. 2nd ed. Oxford: Blackwell Scientific 1982: 485

3 Conrad M, Schwartz F, Young A. Infectious hepatitis - a generalized disease. Am $\mathcal{F} M e d$ 1964; 37: 789-801.

4 Pitcher C, Williams $R$. Reduced red cell survival in jaundice and its relation to abnormal glutathione metabolism. Clin $\mathrm{Sc}$ 1963; $24: 239-45$.

5 Kasper M, Miller W, Jacob H. G6PD-deficiency infectious haemolysis: a complement dependent innocent bystander phenomenon. Br F Haematol 1986; 63: 85-91.

6 Burka E, Weaver Z, Marks P. Clinical spectrum of hemolytic anemia associated with glucose-6-phosphate dehydrogenanemia associated with glucose-6-phosphate dehy

7 Salen G, Goldstein F, Haurani F, Wirts C. Acute hemolytic anemia complicating viral hepatitis in patients with glucose-6-phosphate dehydrogenase deficiency. Ann Intern glucose-6-phosphate dehy

8 Philips S, Silvers N. Glucose-6-phosphate dehydrogenase deficiency, infectious hepatitis, acute hemolysis and renal failure. Ann Intern Med 1969; 70: 99-103.

9 Kattamis C, Tjortjatou F. The hemolytic process of viral hepatitis in children with normal or deficienct glucose-6 phosphate dehydrogenase activity. I Pediatr 1970; 77 : 422-30.

10 Upadhyaya $P$, Nanda $R$, Uberoi $H$, Ahuja I. A comparative study of patients with acute haemolytic anaemia in relation to erythrocyte glucose-6-phosphate dehydrogenase deficito erythrocyte glucose-6-phosphate dehydrogen
ency. $\mathcal{A}$ Assoc Physicians India 1987; 35: 561-4.

11 Eliakim R, Shalev $O$, Menczel J. Hemolytic anaemia as a complication of acute viral hepatitis in glucose-6-phosphate dehydrogenase-deficient and healthy individuals. Isr $\mathcal{f} \mathrm{Med}$ Sci 1983; 19: 1107-9.

12 Hara $\mathrm{K}$, Tagawa $\mathrm{K}$, Unuma T. Acute hemolysis associated with hepatitis A. Gastroenterol f pn 1985; 20: 611-5. 